\title{
INDICIOS DE VARIACIÓN Y CAMBIO EN EL SISTEMA DE CLASIFICACIÓN NOMINAL EN BRIBRI
}

\author{
Carlos Sánchez Avendaño
}

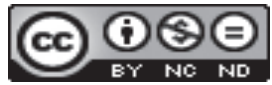

Doi: https://doi.org/10.15517/rfl.v46iExt..43605

URL: https://revistas.ucr.ac.cr/index.php/filyling/index 



\title{
INDICIOS DE VARIACIÓN Y CAMBIO EN EL SISTEMA DE CLASIFICACIÓN NOMINAL EN BRIBRI
}

\author{
SIGNS OF VARIATION AND CHANGE IN THE SYSTEM \\ OF NOMINAL CLASSIFICATION IN BRIBRI
}

\author{
Carlos Sánchez Avendaño
}

\begin{abstract}
RESUMEN
En este artículo se analizan los indicios de variación y cambio del sistema de clasificación nominal en bribri. En esta lengua, los sustantivos se adscriben a clases nominales vinculadas con parámetros como la forma del referente (plana, redonda, alargada) o su carácter humano, entre otros. La clase se realiza por medio de sufijos unidos a las raíces numerales, por lo cual se ha concebido como un sistema de clasificadores numerales. Sin embargo, los paradigmas muestran diferencias formales entre sí hasta ciertos números. Por este motivo, se ha sospechado que, debido al proceso de desplazamiento del idioma, algunas clases han perdido la marcación propia en algunos casos. Con el fin de evaluar esta hipótesis, recurrimos a las descripciones y a los corpus discursivos más antiguos. Además, recogimos datos actuales de la competencia lingüística de diversos hablantes. El examen de la documentación histórica evidencia que los paradigmas no han perdido la marcación desde finales del siglo XIX. Por su parte, los datos actuales muestran que la tendencia de cambio vinculado al desplazamiento consiste en extender la marcación de la clase plana a otras.

Palabras clave: bribri; clasificación nominal; clasificadores numerales; desplazamiento de lenguas; obsolescencia estructural.
\end{abstract}

\begin{abstract}
In this article we analyse the signs of variation and change of the nominal classification system in Bribri. In this language, nouns are assigned to nominal classes related to parameters such as the shape of the referent (flat, round, long) or its human character, among others. The class is realized by means of suffixes attached to the numeral roots, therefore it has been conceived as a system of numeral classifiers. However, the paradigms show formal differences up to certain numbers. For this reason, it has been suspected that, due to the shift process of the language, some classes have lost their own marking in some cases. In order to evaluate this hypothesis, we turned to the oldest descriptions and discursive corpus. In addition, we collected current date on the linguistic competence of several speakers. The examination of the historical documentation shows that the paradigms have not lost their marking since the end of the $19^{\text {th }}$ century. On the other hand, the current data show that the tendency of change linked to the shift process consists of extending the marking of the flat class to others.

Keywords: Bribri; nominal classification; numeral classifiers; language shift; structural obsolescence.
\end{abstract}

Dr. Carlos Sánchez Avendaño. Profesor de la Escuela de Filología, Lingüística y Literatura de la Universidad de Costa Rica. San José, Costa Rica.

Correo electrónico: carlos.sanaven@gmail.com 


\section{Introducción}

El bribri, lengua de la familia lingüística chibcha (Constenla, 2008), es hablado en los cantones de Talamanca y de Buenos Aires, en Costa Rica, así como en zonas limítrofes con Panamá. Se suelen reconocer tres geolectos de este idioma, los cuales, siguiendo a Jara (2018), se denominan de acuerdo con una de las regiones donde se hablan: Amubre, Coroma y Salitre.

El tema gramatical del que trata el presente artículo ha sido abordado con relativa profundidad en varios trabajos, pero casi siempre desde una perspectiva descriptiva sincrónica y con apenas algunos comentarios marginales relativos al cambio lingüístico, la gramaticalización, la variación y la obsolescencia tanto del subsistema morfosintáctico de clasificación nominal como del de numeración, comúnmente bajo la etiqueta de "clasificadores numerales" o simplemente de "numeración".

En este sentido, nuestro trabajo constituye el primer análisis detallado de los indicios de variación y cambio que se pueden rastrear tanto en la documentación y en las descripciones más antiguas de la lengua, como en datos recogidos de hablantes de diferentes generaciones y niveles de competencia lingüística, con el fin de evaluar ciertas hipótesis acerca de si este subsistema ha atravesado por un proceso de simplificación vinculado con el desplazamiento de la lengua.

\section{El sistema de clasificación nominal en bribri}

El que denominamos sistema "tradicional actual" de clasificación nominal del bribri corresponde al que se describe en las publicaciones de corte lingüístico profesional que se han ocupado del tema desde finales de la década de 1970 (Constenla, Margery, Morales y Pereira, 1978; Constenla, Margery, Morales y Torres, 1979; Constenla, Elizondo y Pereira, 1998; Jara, 2018; Jara y García, 2009 y 2013; Krohn, 2014; Margery, 1982): en esta lengua, los sustantivos se categorizan en varias clases (de once a doce, según el geolecto) vinculadas con propiedades de los referentes (básicamente, su forma, su ontología y su agrupación).

Este sistema se realiza de manera concomitante con el sistema de numeración: al conjunto de raíces que codifican el valor numérico se sufijan los clasificadores nominales relativos a cada clase. Por este motivo, a veces se ha denominado simplemente sistema de clasificación numeral y la categorización nominal propiamente se ha tratado como parte de la descripción del sistema numeral. En este sentido, aunque la consideración de que se trata de una propiedad de los sustantivos y no de los cuantificadores se halla explícita en publicaciones como Margery (1982) y Constenla et al. (1998), la gramática descriptiva de Jara (2018) constituye el tratamiento pormenorizado más completo de la clasificación nominal del bribri como una propiedad de los sustantivos independiente del sistema de cuantificación como tal.

Conviene insistir en que se trata de dos subsistemas gramaticales diferentes (sistema numeral y sistema de clasificación nominal) que, en su realización, se manifestan juntos: no es posible contar sin emplear una marcación morfológica de clase nominal (es decir, las raíces numerales nunca aparecen solas) ni la clasificación nominal suele manifestarse sin las raíces numerales (excepto en los cuantificadores interrogativos, ciertos pronombres indefinidos y distributivos, y en nominalizaciones; ver Constenla et al., 1998), pero constituyen dos dimensiones semánticas distintas con codificación lexicogramatical en la lengua.

La asignación obligatoria de un sustantivo a una clase nominal depende de que este sea contable (Jara, 2018). Por este motivo, la categorización debe concebirse como una propiedad 
consustancial a cierto tipo de sustantivos. Hay que notar, empero, que algunos sustantivos pueden asignarse a distintas clases y, con ello, variar su significado, a la vez que es necesario recalcar que los sustantivos no contables no forman parte de este sistema y, si lo hacen, en realidad es porque pueden ser tanto contables como continuos, con diferencias semánticas de por medio (Jara, 2018).

Siguiendo la clasificación de Krohn (2014), quien se basa en la tipología y las consideraciones teóricas de Grinevald (2007), se habla de cinco paradigmas de clasificadores numerales sortales (los relativos a entidades individuales), presentes en todos los geolectos del bribri: clase humana, clase redonda, clase alargada, clase plana/abstracta y clase de árboles/ plantas en pie. A estas habría que agregar la clase de las edificaciones. En principio, por ende, estas categorías tienen que ver con la forma del referente (redonda, alargada, plana) o con su ontología (edificación, planta en pie). Existen, además, seis clases de clasificadores mensurativos (los que aluden a entidades concebidas en conjuntos) en Coroma (racimos de musáceas, racimos de pejibaye, puños, paquetes/bultos, productos en unidades de peso, y especies o clases), y cinco en Amubre/Salitre (conjuntos, racimos, productos en unidades de peso, paquetes/bultos y especies/clases).

Las descripciones coinciden en indicar que cada clase se caracteriza por un sufijo distinto que se añade a la raíz numeral: $-k$ para la clase redonda, -töm para la clase alargada, $-t$ o - $t k$ para la clase plana/abstracta, $-l$ para la clase humana, $-l k a$ para la clase de árboles/plantas en pie y para los productos en libras o kilos, -yuwak para la clase de racimos de musáceas en

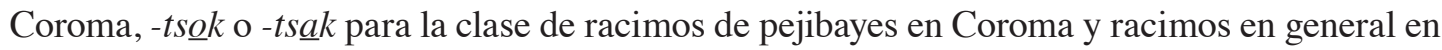
Amubre/Salitre, -yök para conjuntos, -kuak o -kua para la clase de paquetes/bultos, -kue para casas/edificaciones, y -ltë para la categoría de especies o clases.

En lo que respecta a la aparición conjunta de las raíces numerales con los sufijos clasificadores nominales sortales, la distinción morfológica únicamente se codifica consistentemente en la clase alargada hasta el número nueve en el geolecto de Coroma (Jara, 2018) y hasta el diez en los de Amubre y Salitre (Constenla et al., 1998; Margery, 1982), mientras que la clase redonda coincide morfológicamente con la clase humana a partir del número tres, y la clase plana/abstracta se homologa también a la clase humana a partir del número cuatro en todas las variedades del idioma (Constenla et al., 1998; Jara, 2018; Margery, 1982). Por su parte, la clase humana presenta el sufijo - $l$ hasta el número ocho. Para la clase de árboles/plantas en pie, se han documentado formas numeral + clasificador hasta cinco en la variedad de Coroma (Jara, 2018) y en Amubre/Salitre hasta diez (Margery, 1982) o hasta nueve (Constenla et al., 1998).

En la Tabla 1 se consignan las formas de las seis clases sortales hasta el número diez ${ }^{1}$ en las distintas variedades geolectales descritas: para las variedades de Amubre y Salitre según se consignan en Constenla et al. (1998); para la variedad de Coroma de acuerdo con Jara $(2018)^{2}$. Se incluye en primer lugar la forma registrada en Amubre y Salitre, seguida

1 Los números superiores a diez se construyen uniendo el numeral dabòm 'diez' y los numerales de conjuntos, contando de diez en diez. Así, por ejemplo, 'veinte' se expresa dabòm böyök, 'cien' es dabòm dabòbyök, y 'mil' es dabòm dabòbyök dabòbyök. Los números intermedios se construyen con un procedimiento de suma: se agrega kí 'más' y la forma numeral + clasificador del uno al nueve de la clase correspondiente a lo que se esté contando (Constenla et al., 1998; Jara, 2018).

2 Debido a que las fuentes emplean distintas soluciones gráficas para marcar la nasalidad de las vocales 
de una barra inclinada y a continuación la forma documentada para Coroma. Si las formas coinciden en todos los geolectos, solo se consigna una vez. Si una forma es considerada por los autores como inexistente en alguna de las variedades, se coloca un guion corto (-) en el espacio correspondiente.

Tabla 1. Clasificadores numerales de tipo sortal

(Elaborado con base en Constenla et al. (1998) y Jara (2018))

\begin{tabular}{|c|c|c|c|c|c|c|}
\hline & $\begin{array}{c}\text { Clase } \\
\text { humana }\end{array}$ & $\begin{array}{c}\text { Clase } \\
\text { redonda }\end{array}$ & $\begin{array}{c}\text { Clase plana } y \\
\text { abstracta }\end{array}$ & $\begin{array}{c}\text { Clase } \\
\text { alargada }\end{array}$ & $\begin{array}{c}\text { Clase de } \\
\text { árboles/ } \\
\text { plantas en } \\
\text { pie }\end{array}$ & $\begin{array}{c}\text { Clase de } \\
\text { edificaciones }\end{array}$ \\
\hline & Sufijo: $-l$ & Sufijo: $-k$ & Sufijo: $-t k a-t$ & Sufijo: -töm & $\begin{array}{c}\text { Sufijo: } \\
\text {-lka }\end{array}$ & Sufijo: -tkue \\
\hline 1 & e'köl / èköl & e'k / èk & e'tk, e’t / èt & e’töm / ètöm & elka & e'tkue \\
\hline 2 & bốl & bök & bö̀tk / bö̀t & bồtöm & bốlka & bötkue \\
\hline 3 & mañál & mañál & mañàtk / mañàt & mañàtöm & mañálka & mañàtkue \\
\hline 4 & tkël / tchël & tkël / tchël & tkë́l / tchël & $\begin{array}{l}\text { tkềtöm / } \\
\text { tchềtöm }\end{array}$ & $\begin{array}{l}\text { tkếlka / } \\
\text { tchếlka }\end{array}$ & tkềtkue \\
\hline 5 & skél & skél & skél & skèttöm & skélka & skèttkue \\
\hline 6 & tèröl & tèröl & tèröl & tèktöm & tèrölka / - & tèltkue \\
\hline 7 & kúl & kúl & kúl & kùktöm & kúlka / - & kùtkue \\
\hline 8 & pàköl & pàköl & pàköl & pàktöm & pàkölka / - & pàköltkue \\
\hline 9 & sulìtu & sulìtu & sulìtu & sulìtöm & sulitúlka / - & sulitöltkue \\
\hline 10 & dabòm & dabòm & dabòm & $\begin{array}{l}\text { dabòptöm/ } \\
\text { dabòm }\end{array}$ & dabòlka / - & dabòtkue \\
\hline
\end{tabular}

En los paradigmas mensurativos, la marcación morfológica de la clase en Coroma se mantiene hasta el límite en el que se cuente en cada caso: hasta cinco los racimos de musáceas (bananos, plátanos, etc.), las especies/clases (genéricos de plantas o animales) y los paquetes/ bultos; hasta tres en la clase de los racimos de pejibaye; y hasta nueve en la clase de los puños (entidades que caben en un puño, como el arroz) (Jara, 2018; Krohn, 2014), mientras que para las otras variedades se documentaron números hasta diez en todas estas clases (Margery, 1982). El paradigma mensurativo de clasificadores para contar unidades de peso (libras, kilos, etc.) coindice morfológicamente con el de plantas en pie.

Al comparar las distintas variedades, se aprecia que en Coroma se encuentran varias series mensurativas con una cantidad de cuantificadores más limitada que la que se ha documentado para otros geolectos. Krohn (2014) supone que se ha producido una reducción; es decir, existe la posibilidad de que en la variedad de Coroma hayan desaparecido los números mayores a cinco para categorías como paquetes y especies, mientras que en las de Amubre y Salitre sí se habrían conservado.

Lo mismo podría haber sucedido (en este caso, ya en todas las variedades) no con la unidad numeral + clasificador, sino con la distinción morfológica de las clases sortales, que se habría dejado de marcar en ciertos números, sin que se haya perdido el numeral mismo. Dicho de otra manera, podría pensarse que la marcación morfológica propia de ciertas clases se ha sustituido por la de otras, a lo cual Krohn (2014, p. 236) se refiere como "formas supletivas". Krohn (2015, p. 21) incluso afirma que

(subrayado, virgulilla o gancho polaco), hemos optado por uniformar las formas y emplear en todos los casos el subrayado. 
en el bribri de Coroma el clasificador REDONDO se encuentra a punto de caer en desuso; solamente los numerales 'uno' y ‘dos' reciben el clasificador REDONDO mientras que los numerales mayores en este paradigma se expresan con formas supletivas tomadas del paradigma HUMANO.

El autor no argumenta ni brinda datos que apoyen su aseveración acerca de la inminente pérdida del paradigma de la clase redonda con marcación propia, ni de la supuesta toma de formas de la clase humana para suplir tal pérdida.

Por otra parte, en la variedad de Coroma existe la distinción entre la clase para contar racimos de musáceas frente a la clase para contar racimos de pejibaye, la cual no es mencionada en otras fuentes, en las que más bien solo se consigna una clase general para racimos caracterizada por el sufijo -ts $\underline{a} k$, correspondiente a la que en el geolecto de Coroma solo se emplea para contar racimos de pejibaye y no de musáceas. Kronh (2014) arguye que la clase para racimos de pejibaye sería o una innovación en la variedad de Coroma o una categoría desaparecida en los otros geolectos.

En efecto, al no existir claridad con respecto a la vía de la gramaticalización, es posible pensar que ambas explicaciones son plausibles, tanto para la inexistencia de determinadas clases en una u otra variedad (si es que efectivamente no existen), como para la discrepancia en el número hasta el cual se puede contar con marcación morfológica propia en algunas clases. En otras palabras, podría tratarse de que en una variedad se gramaticalizó una distinción y en otras no, o bien de que en una esta se perdió y en otra se conservó. De igual manera, podría haber ocurrido que en Coroma el número de miembros con marcación morfológica propia de cada paradigma se haya reducido, o bien que en Amubre/Salitre se haya extendido.

Los diversos autores que se han ocupado con detalle del tema no han propuesto una hipótesis clara al respecto. Krohn (2014) únicamente menciona la posibilidad de que, en la actualidad, los hablantes jóvenes no empleen la marcación morfológica propia y que hayan extendido aun más la marcación de determinadas clases, así como que se estén abandonando ciertas categorizaciones o que el alcance semántico de cada clase se encuentre en proceso de cambio.

En Constenla et al. (1998, pp. 69, 75), por su parte, no se formula ninguna hipótesis sobre el cambio, sino que tan solo se describe el hecho de que la marcación morfológica es igual en las clases plana, redonda y humana a partir de determinados números en términos de que las formas “coinciden". Jara (2018, p. 123), por su lado, indica que los cuantificadores sin marcación morfológica propia en las clases plana y redonda "corresponden a formas numerales que no se utilizan en la actualidad, si bien es posible que existieran en el pasado", y anota que para contar elementos de esas categorías "se utilizan los numerales de la clase humana".

Con respecto a la cuestión de la presunta pérdida de formas, si pensamos que estamos ante procesos de gramaticalización, bien podría ser que un cambio esté más avanzado en un geolecto que en otro; o bien, si nos situamos en el contexto del desplazamiento, podría suponerse que la reducción de los subsistemas gramaticales está más avanzada en unas variedades que en otras. Debe insistirse, en todo caso, en que ni la vía de la gramaticalización ni la del cambio por obsolescencia se han descrito con detalle, por lo que cualquier afirmación al respecto requiere del examen de todos los datos disponibles y de investigación de campo.

Con el fin de intentar esclarecer el asunto, conviene revisar las descripciones y la documentación "históricas" (esto es, las previas a la etapa que hemos denominado de trabajo lingüístico profesional), así como llevar a cabo estudios sistemáticos de "obsolescencia estructural”. 


\section{Datos de la documentación histórica}

Con excepción de ciertas fuentes que aportan poco al tema que nos atañe (Gagini, 1917; Thiel, 1882), las descripciones y la documentación más antiguas del bribri pueden brindar pistas acerca de la vía del cambio lingüístico y, sobre todo, acerca de si los paradigmas de las distintas clases han perdido elementos, al menos desde finales del siglo XIX. En la Tabla 2 se recoge la información al respecto ${ }^{3}$ de las clases nominales en Pittier (1898) y Lehmann (1920).

Tabla 2. Documentación histórica de las formas numeral + clasificador en bribri ${ }^{4}$

(Elaborado con base en Lehmann (1920) y Pittier (1898))

\begin{tabular}{|c|c|c|c|c|c|c|c|c|c|c|c|}
\hline & & 1 & 2 & 3 & 4 & 5 & 6 & 7 & 8 & 9 & 10 \\
\hline \multirow[t]{6}{*}{ Pittier (1898) } & Personas & ekur & buur & mńór & kúr & skẽr & térul & kuúr & pagul & surí-tu & dábop \\
\hline & $\begin{array}{l}\text { Objetos } \\
\text { redondos }\end{array}$ & ek & buuk/buúk & mńór & kúr & skẽr & térul & kuúr & pagul & surí-tu & dábop \\
\hline & $\begin{array}{l}\text { Animales } \\
\text { pequeños }\end{array}$ & etk & butk & mńatk & kir & & & & & & \\
\hline & $\begin{array}{l}\text { Objetos } \\
\text { largos y } \\
\text { animales } \\
\text { grandes }\end{array}$ & é-tub & bu-tub & mńa-tub & ki-tub & ské-tub & tek-tub & kuk-tub & pak-tub & surí-tub & dẹbop-tub \\
\hline & $\begin{array}{l}\text { Árboles y } \\
\text { plantas }\end{array}$ & iré kar & bur kar & mńór kar & kir kar & skẽr kar & terul kar & kur kar & pagur kar & surí-tu kar & dębop kar \\
\hline & Casas & etk ué & butk ué & mńatk ué & kir ué & skẽr ué & terur ué & kur ué & págur ué & suri-tu ué & dẹbop ué \\
\hline \multirow[t]{7}{*}{$\begin{array}{l}\text { Lehmann } \\
\text { (1920) }\end{array}$} & $\begin{array}{l}\text { Objetos } \\
\text { redondos, } \\
\text { frutos, piedras } \\
\text { y años }\end{array}$ & ák & bōk & mañáł & kál & & & & & & \\
\hline & $\begin{array}{l}\text { Casas, } \\
\text { fogones, } \\
\text { tumbas }\end{array}$ & ǽtkǔě & bốkǔě & mañátkǔĕ & kátkǔě & skálǔẽ & tádǔlǔě & & & & dabốbǔě \\
\hline & $\begin{array}{l}\text { Objetos } \\
\text { alargados, } \\
\text { árboles, ríos, } \\
\text { ganado, } \\
\text { jaguares, } \\
\text { peces, } \\
\text { cuerdas, } \\
\text { flechas, arcos, } \\
\text { cerbatanas }\end{array}$ & átǔb & bốtǔb & & & & & & & & dabớptǔb \\
\hline & $\begin{array}{l}\text { Personas, } \\
\text { dioses }\end{array}$ & źkǔl & bōł & mañắa & kál & & & & & & \\
\hline & $\begin{array}{l}\text { Canastas, } \\
\text { camisas, } \\
\text { pantalones, } \\
\text { dientes, } \\
\text { manos, } \\
\text { pájaros, } \\
\text { meses, } \\
\text { tiempo, días }\end{array}$ & át & bōt & mañắt & kál & & & & & & \\
\hline & $\begin{array}{l}\text { Árboles de } \\
\text { cacao y } \\
\text { árboles } \\
\text { frutales }\end{array}$ & árkał & bốrkał̣ & mañắrkał & kárkał & skárkał & tárkał & kứrkał & & & \\
\hline & Cargas, pesos & ǽdžǔk & bốdžǔu & mañấdžǔu & kǽdžǔk & skǽdžǔk & tźdžǔk & & & & \\
\hline
\end{tabular}

El primer trabajo en documentar los números en bribri es el manuscrito Vocabulario del cabecara, viceyta y terrava, firmado por Jossef Olabarrieta entre 1788 y 1790 (Lehmann, 1920). Los datos bajo el nombre de "viceyta" parecen ser en su mayoría del bribri, aunque muy deficientemente transcritos (Constenla, 2004). En cualquier caso, los números 3 y 4

3 Se consignan los datos con la grafía original, con excepción del diacrítico $<>$ empleado por Lehmann sobre la vocal que él representa con $\langle\mathfrak{x}\rangle$. No hay espacio para tratar con detalle aquí el problema de la grafización, los signos empleados por los diferentes autores y la asistematicidad con que se registran algunos datos.

4 Las casillas vacías en este cuadro corresponden a formas que no son anotadas explícitamente por los respectivos autores, lo cual no significa que no existieran, puesto que a veces más bien se incluye "etc." al final de la lista. 
resultan interesantes. El número 3 mañac no se encuentra en la documentación ni histórica ni profesional, excepto en Tristán (1913). Curiosamente, es la que parece mejor transcrita y bien podría tratarse de una forma antigua propia del número 3-redondo con el sufijo - $k$ (mañáa en la grafización moderna). Asimismo, la forma 4 quiet parece relacionarse con la raíz tké más el sufijo - $t$, forma no documentada en ninguna otra fuente y que bien podría corresponder a una forma propia antigua para 4-plano (tkët en la grafización moderna).

Casi un siglo después, Gabb (1875) será el primero en identificar formas distintas según la entidad contabilizada, que él agrupa en "personal" para humanos y "no personal" para lo demás, aunque no ahonda en el tema ni tampoco es sistemático en la documentación. Las raíces numerales de sus datos son relacionables con las formas modernas, pero lo más interesante es su comentario de que la forma m-nyat para 3 se utiliza para contar todas las cosas, pero que para contar hombres se diría $m$-nyal y, para días, $m$-nyar ${ }^{5}$.

Como se aprecia, entonces, ya desde la década de 1870 no habría existido distinción morfológica entre la clase humana (la "personal" de Gabb) y la actual clase plana (la “impersonal” de Gabb) más allá del número 3. Se trata tan solo de un primer indicio, el cual por supuesto debe tomarse con cautela dada la asistematicidad de su descripción. Así, por ejemplo, no es claro por qué para el número 1 únicamente se registra una forma, ni tampoco es posible explicar por qué no aparecen elementos correspondientes a las actuales clase redonda y clase alargada.

A finales del mismo siglo, Pittier (1898) registra seis "distintos modos de contar", según la forma o naturaleza de los objetos: personas, objetos redondos, animales pequeños, casas, objetos largos y animales largos, árboles y plantas. Es decir, se trata del primer autor en dar cuenta, de manera más amplia, del sistema de clasificación nominal vinculado a los números. La serie para contar personas corresponde fielmente a la actual clase humana (con las diferencias e inconsistencias ortográficas esperables) y, en particular, se aprecia que ya para finales del siglo XIX se documenta la forma correspondiente a las modernas e'köl/èköl del número 1 del paradigma para contar seres humanos.

Para contar objetos largos y animales grandes (el ejemplo que proporciona es stsa 'cuerda'), también documenta formas equivalentes al paradigma actual de la clase alargada. Para contar objetos redondos (el ejemplo que incluye es $a \check{s}$ 'naranja'), Pittier (1898) consigna las formas para 1, 2 y 3, y aclara que de ahí en adelante se usan las mismas formas que para contar gente. Para contar animales pequeños (el ejemplo que proporciona es $d u$ 'pájaro'), consigna formas de 1 a 4 y señala que de ahí en adelante se usan los mismos números que para contar personas. Nótese que las formas mñor '3-redondo' y kir '4-alargado' son iguales a las de la clase para contar personas; es decir, las series para contar objetos redondos y animales pequeños corresponden con exactitud, respectivamente, a las actuales clase redonda y clase plana.

En lo relativo a la serie para contar árboles/plantas, utiliza el ejemplo de tsirú 'cacao' y en una publicación posterior afirma: "In counting trees, the name of the special tree (here tsirú, cacao) precedes the numeral, which is followed by the generic name kar, tree" (Pittier,

$5 \quad$ Las formas terminadas en $l$ y $r$ correponden a la misma palabra en bribri con el sonido vibrante lateral (interpretado como lateral o como vibrante simple en las distintas fuentes históricas). La alternancia en la escritura entre $r$ y $l$ se origina en la dificultad de estos autores para determinar la naturaleza del segmento lateral vibrante $/ \mathrm{d} / \mathrm{del}$ bribri, que unas veces se interpreta como lateral (escritura $<\mathrm{l}>$ ) y otras como vibrante simple (escritura $<\mathrm{r}>$ ). 
1904, p. 451). De este modo, tsirú iré kar corresponde a '1 árbol de cacao', tsirú bur kar '2 árboles de cacao', etc. Las formas de los demás numerales corresponden (salvo detalles debidos a inconsistencias gráficas) a los números para contar personas.

Así, la única forma "extraña" es iré '1', que bien podría corresponder a la hipotética forma $e$ 'llèl o a alguna similar, más regular que la registrada e'köllèköl de la clase humana, y que claramente remite al tema ${ }^{6}$ él que se encuentra en la forma élka de la actual clase de plantas en pie. Cabe notar que para ‘once árboles de cacao', Pittier (1898) consigna tsirú dębop ki er kar, construcción en la que sí aparece documentada la forma er (e’l / èl en la grafización moderna), lo que vendría a sustentar la posibilidad de que esta habría sido la forma base original para el número 1, cuyos restos solo quedan actualmente en la forma élka, pero que en los tiempos de Pittier todavía se podía identificar como vocablo independiente, al menos en la construcción mencionada.

La descripción de Pittier (1898) permite reconstruir el canal de gramaticalización de este paradigma. El sustantivo genérico kàl 'árbol' habría entrado en una construcción sintáctica del siguiente tipo: sustantivo (nombre específico del árbol), seguido de numeral + clasificador (tema, que corresponde a la clase humana moderna), seguido del sustantivo genérico kàl. Primero se habría tratado de una construcción en la que el sustantivo genérico kàl habría funcionado como clasificador nominal, pero, para finales del siglo XIX, entre el numeral y el genérico kàl se habría conformado una especie de estructura compuesta.

Finalmente, el proceso habría desembocado en la integración morfológica total entre numeral y sustantivo genérico; este último desgastado fonológicamente en la forma $k a$ y convertido en un sufijo. Así, la explicación en Constenla et al. (1979) de que el sufijo de esta clase es - $k a$ (y no - lka, como se describiría posteriormente) y que se agrega a los números de la clase humana resulta acorde con el canal de gramaticalización, el cual sería el siguiente: numeral + clasificador + sustantivo genérico kàl 'árbol' > tema + sufijo - $k a$. La vigencia de esta construcción es descrita para mediados del siglo XX por Stone (1993, pp. 54-55), quien afirma que algunos sustantivos van seguidos por el número y "un sufijo o una palabra", de modo que "un determinado árbol como el pejibaye, va seguido por el número y por el nombre genérico "árbol"”.

Pittier (1898) también consigna un "modo de contar" casas por medio de una construcción sintáctica análoga a la de contar árboles, pero con la serie numeral para contar animales pequeños (aunque él en realidad no lo explicita así y de hecho hay inconsistencias gráficas entre las formas que consigna para ambas series): hú 'casa' + numeral de animales pequeños + ué. Este autor considera la forma ué un sufijo, aunque lo escribe separado del numeral: hú etk ué '1 casa', hú butk ué '2 casas' y así por el estilo.

La forma ué parece provenir del lexema ù 'casa', en su alomorfo denominado de referencia particularizada, un tipo de alternancia morfológica que aparece en relaciones genitivas "para señalar que el sustantivo se mencionó anteriormente en relación con determinado hecho" o "una relación de posesión que caracteriza al objeto poseído, frente a la posesión normal, que no tiene esta connotación" (Constenla et al., 1998, pp. 54-55). Esta interpretación se encuentra con total explicitud en Jara (2018), para quien la clase para contar casas es una subcategoría de la clase plana, formada con el tema de la clase plana seguido de $u e$.

6 Denominamos "tema" a la forma numeral + clasificador que sirve de base para construir otros paradigmas agregando un nuevo sufijo de clase. 
Se aprecia, además, que se utiliza como tema la forma numeral + clase de "animales pequeños" consistentemente; esto es, a partir del número 4 no se emplean temas con el sufijo - $t k$, sino con $-l$ ( 1 o r en la escritura de Pittier), similares a las formas de las clases para contar personas y objetos redondos (tanto en la documentación de Pittier como en la moderna). En este sentido, la documentación de Pittier (1898) difiere enormemente de la de Constenla et al. (1998), en la que sí aparecen temas con -tk de 1 a 10, lo cual hace pensar que quizás las formas registradas en Constenla et al. (1998) se desarrollaron por una paradigmatización relativamente reciente, pues no parece probable que se hayan perdido las formas propias de los números de la clase plana tanto en la clase plana propiamente como en la clase de edificaciones a finales del siglo XIX, y que luego se hayan "repuesto" únicamente como base para formar la clase de edificaciones en tiempos recientes.

Pocos años después, Tristán (1913) recoge dos series de numerales de 1 a 10. En una apunta, a modo de traducción, el equivalente a 'una naranja' (ash en su escritura del bribri) y de ahí en adelante; del mismo modo, anota el equivalente a 'un palo' (kar en su escritura) y de ahí en adelante. En general, su documentación se vincula sin mayores problemas con la documentación profesional; sin embargo, sobresale la forma mañak para 3 de la clase "ash", la cual está construida con el morfema $-k$ propio de la clase redonda y no con $-l$, como en la documentación desde finales de la década de 1970. Coincide en este aspecto, por ende, con lo recogido a finales del siglo XVIII en la lista léxica de Olabarrieta y hace pensar que sí habría existido una forma para 3-redondo con sufijo de clase $-k$. No queda claro por qué en Gabb, Thiel y Pittier no se registró esta forma, pero podría suponerse que, por alguna razón, Tristán logró registrar la pervivencia de una forma antigua -la cual, aparentemente, terminó desapareciendo- que competía con la que llegó a afianzarse (con sufijo -l).

Lehmann (1920) $)^{7}$ constituye el siguiente registro histórico que se ocupa con detalle de los números. En general, su documentación coindice con la moderna, salvo en algunos detalles que conviene destacar. En primer lugar, las formas numeral + clasificador de Lehmann corresponden a las modernas en lo concerniente a la clase redonda, la clase alargada, la clase humana, la clase plana y conjuntos (que Lehmann etiqueta como "cargas y pesos").

Aparte de las diferencias de escritura, los datos divergentes más interesantes se encuentran con respecto a la clase de edificaciones y la de plantas en pie. Lehmann recoge formas para la clase de edificaciones construidas con el tema de la clase plana más -ue hasta 4 y, a partir de 5, los temas coindicen con la clase humana. En este sentido, no solo difiere de lo documentado en Constenla et al. (1998), sino también de los datos de Pitter (1898), para quien la forma para 4 se hace con un tema terminado en r; es decir, para Pittier ya a partir del numeral para 4 se usa como base la misma forma de la clase humana. Los datos de Lehmann (1920), por lo tanto, apuntarían a que el hablante con quien trabajó ya emplearía formas con mayor avance en la paradigmatización, pero aún con un paradigma con morfología propia incompleto en relación con lo documentado en Constenla et al. (1998).

En cuanto a la clase de plantas en pie, los datos de Lehmann coinciden con los de Pittier en lo concerniente a que el sufijo de clase seguía mostrando la terminación $l$ ( $\downarrow$, en la escritura de Lehmann), claramente aún correspondiente a la forma del sustantivo de la que proviene $(k a ̀ l)$. La única diferencia destacable es que su forma para 6 (tárkał ) parece mostrar una forma base ter y no teröl, como se documenta no solo en Constenla et al. (1998), sino

7 Existe traducción al español de parte de esta obra: Künne y Mackenbach (2019). 
también en Pittier (1898), lo que indicaría que ambas coexistían antiguamente: una con -r y otra con -röl. Esta interpretación se corrobora con los datos del Evangelio (1905), en los que aparece también ter (en alternancia con terol) como numeral de la clase redonda (ver Tabla 3).

Finalmente, Bozzoli (1979), quien recogió sus datos con dos hablantes jóvenes de Salitre, se ajusta a grandes rasgos al sistema que hemos denominado profesional, pero agrega una serie que no se había registrado en ninguna fuente histórica anterior (la clase para contar paquetes o cosas envueltas) y otra que no ha sido mencionada tampoco en las descripciones profesionales: la clase para contar entidades en masa, la cual parece formarse a partir de la sufijación del sustantivo genérico chakà 'masa, sustancia semisólida o sólida' al tema de la clase plana (así lo afirma Bozzoli, pero en los numerales 1 y 2 parece usarse directamente la raíz numeral: echkam y böchkam). Se requiere de investigación sobre la naturaleza de esta clase y para confirmar que efectivamente existe en la actualidad.

Un aspecto más que vale la pena destacar de la documentación de Bozzoli (1979) es su indicación de que, a partir del numeral para 6, en la clase alargada, la de árboles, la de racimos, la redonda, la humana, la de paquetes/cosas envueltas y la de masa, se emplean formas sin el morfema correspondiente a la categoría nominal propia y, en su lugar, aparecen las formas de lo que ella denomina "la manera corriente", que, por los ejemplos que consigna y por la morfología, corresponde a la clase plana. Lamentablemente, Bozzoli no justifica su terminología, de modo que no es posible saber con certeza a qué se refiere con "manera corriente", si bien no deja de ser interesante que al parecer la considera la serie neutra o más general.

En todo caso, lo importante es que los hablantes salitreños de la década de 1970 con los que recogió sus datos no solo empleaban paradigmas sin morfología propia para cada clase en las categorías de redondo y plano, sino también en todas las demás, a partir de cierto número. Que se trate de obsolescencia o de paradigmatización incompleta dependería del estado de la gramaticalización y del avance de la paradigmatización para mediados del siglo XIX, momento para el cual se produjo la migración de población bribri de Talamanca a la actual localidad de Salitre (Sánchez, 2009).

Con respecto a datos que podemos extraer de corpus discursivos, hasta donde sabemos, los más antiguos del bribri consisten en unos textos breves de tradición oral transcritos por Pittier (1898), pero estos poco aportan al tema que nos ocupa. El siguiente corpus está constituido por la traducción del Evangelio de san Juan por parte de un hablante nativo del bribri: Guillermo Gabb (1905). En el siguiente cuadro se sistematizan los datos relativos a las clases nominales.

Tabla 3. Números en el Evangelio según san Juan (Gabb, 1905)

\begin{tabular}{|c|l|l|l|l|l|}
\hline & $\begin{array}{l}\text { Clase } \\
\text { humana } \\
1\end{array}$ & $\begin{array}{l}\text { Clase } \\
\text { redonda }\end{array}$ & Clase plana & $\begin{array}{l}\text { Clase } \\
\text { alargada }\end{array}$ & Conjuntos \\
\hline 2 & bor bur & bok & et & $\begin{array}{l}\text { éyuk eyuk } \\
\text { éyok }\end{array}$ \\
\hline 3 & & mañar & mañat & botub & boyok \\
\hline 4 & & & tker & & mãnayuk \\
\hline 5 & sker & & sker $\sim$ sker & & $\begin{array}{l}\text { skeyuk } \sim \text { skéyuk } \\
\text { skéyok }\end{array}$ \\
\hline 6 & & ter $\sim$ terol & térol & & \\
\hline 7 & & kur & & \\
\hline 8 & & pagur & & & $\begin{array}{l}\text { dabób-yuk } \\
\text { dabob yok } \\
\text { dabobyuk }\end{array}$ \\
\hline 10 & & & dabob & & \\
\hline
\end{tabular}


La casi total coincidencia de estos datos con la documentación moderna es clara. En particular, se muestra cómo para Gabb las formas 3-redondo y 8-redondo ya terminaban en - $l$, al igual que 4-plano y 5-plano; es decir, a partir de 3-redondo y 4-plano, la marcación del paradigma de redondo y la de plano corresponden a la de la clase humana, exactamente igual a como ocurre en la actualidad. Del mismo modo, se utiliza la forma moderna para 1-humano (ekur) y 10-redondo (dabob), así como el alomorfo - $t$ para la clase plana (en lugar de -tk). La única discrepancia -ya señalada-corresponde a la forma ter para 6, en alternancia con terol, indicio de la pervivencia de una forma antigua.

En cuanto a la categorización semántica, la mayoría de los sustantivos que aparecen con un numeral en el Evangelio (1905) se adscriben a clases equivalentes a las descritas en las distintas fuentes. Eso sí, resulta llamativa la adscripción del sustantivo nima 'pescado, pez' a dos clases: la plana (aparece con los numerales et '1-plano' y mañat '3-plano', en una ocasión cada uno) y la alargada (aparece una vez con el numeral botub '2-alargado'). En las descripciones profesionales, este sustantivo siempre se ha adscrito a la clase alargada. Esta oscilación podría revelar que la asignación de clase es susceptible de variar en algunos casos, como veremos más adelante.

\section{Variación y cambio lingüístico en el contexto del desplazamiento actual del bribri}

En este apartado, examinamos algunos datos recogidos en el contexto actual de desplazamiento de la lengua, con el fin de determinar si los subsistemas de clasificadores sortales han perdido marcaciones morfológicas para los números mayores a dos o tres en el caso de las clases redonda y plana, respectivamente. Es decir, se intenta establecer si estamos ante un proceso de cambio por obsolescencia.

Para este propósito, se diseñó un instrumento para recoger la información con hablantes de distintas edades. Debe entenderse, por lo tanto, que se trata de datos provenientes de una situación experimental y no de discurso espontáneo. La elicitación de la forma numeral + clasificador se realizó por medio de un estímulo visual: a cada hablante se le presentaron 45 tarjetas con ilustraciones o fotografías de diferentes entidades y en cantidades de 1 a $3^{8}$, distribuidas de modo aleatorio en cuanto a la cantidad y a la categoría nominal, y a cada persona se le solicitó que dijera la cantidad en voz alta.

En este sentido, la situación experimental podría haber resultado novedosa en sí misma: se pedía que, en vez de contar objetos y animales "reales", se contaran objetos representados. No puede negarse que ello implicó solicitarles a algunos individuos realizar una tarea lingüística poco usual en su cultura; sin embargo, se puede afirmar que esta más bien enriqueció los datos y no parece haber sido asumida como una tarea extraña o de mayor complejidad por la naturaleza del estímulo, puesto que incluso los hablantes mayores pudieron llevarla a cabo sin problema.

Se aplicó el instrumento a cuatro hablantes mayores de 50 años, a tres hablantes de entre 12 y 13 años, y a dos adultos de entre 30 y 40 años. Cuatro de los hablantes mayores de 50 años están emparentados con alguno de los adolescentes. Los nueve viven en poblados

$8 \quad$ Ante la imposibilidad de representarlas visualmente, se recogieron dos formas por traducción: 'tres años' y 'tres meses'. 
contiguos y suelen mantener algún grado de interacción frecuente. Tanto los mayores como los adolescentes son hablantes de la variedad de Coroma, mientras que los dos adultos provienen de familias hablantes de la variedad de Amubre. En gran medida, esto determina sus distintas biografías lingüísticas. A continuación, se describen someramente algunos detalles, basados tanto en una entrevista que se les realizó con anterioridad al experimento como en nuestra observación in situ.

Los cuatro hablantes mayores de 50 años son bilingües sucesivos, con el bribri como su primera lengua. En la actualidad, suelen emplear cotidianamente el español con relativa frecuencia, pero también emplean mucho el bribri en la comunicación diaria. El más anciano de los cuatro desempeña un cargo tradicional dentro de la cultura (awá 'médico tradicional'), por lo cual es previsible que su crianza haya estado enmarcada en un contexto sociocultural de menos cambios y menos influencia de la cultura hispanocostarricense. Cabe anotar que, pese a su edad, dos de los hablantes parecen haber perdido alguna competencia en bribri, lo cual se hace patente en su empleo de los clasificadores.

Los tres adolescentes también pueden interactuar en bribri. Su competencia receptiva parece ser alta y todos parecen ser capaces de mantener una conversación. No obstante, si bien puede ser que se trate de bilingües simultáneos, es probable que su competencia en español haya ido aumentando paulatinamente desde la infancia temprana, en gran medida por influencia de la escolarización. En la conversación entre ellos parece imperar el uso del español, pero recurren al bribri en la interacción con familiares y otras personas mayores de la comunidad. Existen indicios de que se trata de semihablantes de alta competencia, o bien de hablantes jóvenes, de acuerdo con la tipología de hablantes de lenguas en peligro (Grinevald y Bert, 2011).

Por su parte, los dos hablantes adultos de entre 30 y 40 años viven en la región en la que se habla la variedad de Coroma, pero se criaron en otros poblados. Uno de ellos declaró que su abuela era hablante, pero que él no adquirió el bribri tempranamente. Se considera a sí mismo un hablante de competencia productiva y receptiva reducida. La otra hablante afirmó que su primera lengua era el español y que adquirió el bribri posteriormente. Si bien considera que emplea el bribri diariamente, también siente que se le dificulta su uso. En particular, por ejemplo, es consciente de las distintas series para contar, pero asevera que posiblemente emplee un solo paradigma numeral: "yo cuento hasta...cuento bastante en bribri, pero lo que no sé es como el redondo. Digamos, si voy a decir que esas sillas son dos, yo digo böt, y a esas dos bolsas les digo böt, digamos igual. No tengo la distinción".

Debe subrayarse que esta es una primera investigación exploratoria sobre el tema y que no se consideraron algunas variables. Por ejemplo, si bien recogimos datos de tres mujeres y seis hombres, la variable género no se consideró ni para la selección de los participantes ni en el análisis de los datos. Además, la muestra se escogió por accesibilidad de los hablantes: se trata de personas que aceptaron participar en la situación experimental por estar interesadas en el prototipo de juego para practicar el sistema numeral que estábamos diseñando en el momento de recoger los datos (Sánchez, 2019).

En cuanto a la situación sociolingüística, claramente estamos ante una lengua en un estado muy distinto al descrito y documentado a finales del siglo XIX y en la primera mitad del siglo XX. Se trata ahora de un contexto de desplazamiento constante del idioma en sus dos manifestaciones: pérdida de dominios de uso (que se comparten ahora con el español o incluso en los que predomina este casi por completo) y reducción intergeneracional de la competencia 
de los hablantes (debido a que la socialización linguiística y la adquisición concomitante del bribri se realiza, en el mejor de los casos, de forma bilingüe, y, en el peor, exclusivamente en español). En cualquier caso, con casi total seguridad, el desplazamiento del bribri no comenzó antes de la segunda mitad del siglo XX (Sánchez, 2009).

Debe notarse que se esperaría que los dos hablantes adultos correspondieran a una generación de bilingüismo relativamente simultáneo (o al menos con la adquisición del español a una edad temprana, posiblemente coincidente con el inicio de la escolarización a los 7 años) y relativamente equilibrado (como de hecho ocurre, según nuestras observaciones, con muchos de los adultos de Coroma en su mismo rango de edad, quienes pueden interactuar sin mayor problema en ambas lenguas), así como que las generaciones menores a ellos mostraran menor competencia y menor empleo del bribri. Por el contrario, los tres adolescentes muestran mayor competencia receptiva y productiva en bribri que los dos adultos, por provenir estos de otros poblados en los que el desplazamiento del idioma se encuentra mucho más avanzado.

En suma, es claro que los usos y la competencia actuales de la lengua bribri se enmarcan en una situación global de desplazamiento y que, por consiguiente, es esperable que se hallen fenómenos de cambio lingüístico vinculados a este proceso, lo que comúnmente se conoce como "obsolescencia estructural" (Jones y Singh, 2005). En este, surgen innovaciones, simplificaciones, reducciones y generalizaciones vinculadas con la disminución progresiva del uso del idioma, su adquisición en situaciones no óptimas o incluso el cese de la socialización en la lengua desplazada durante la primera infancia, la interacción predominante en la lengua reemplazante y la interacción no participativa en la lengua desplazada.

Para atribuirle a una reducción o a una simplificación en un subsistema gramatical una naturaleza "obsolescente" debe tenerse muy en cuenta, entonces, que el cambio debe desarrollarse en una situación de desplazamiento de la lengua (Palosaari y Campbell, 2011; Jones y Singh, 2005). Por ello, se deben comparar los elementos o subsistemas de un estadio $\mathrm{B}$ de la lengua (competencia y usos de hablantes cuya adquisición y empleo han tenido lugar una vez ya comenzado y avanzado el desplazamiento) con los de un estadio A (documentación previa al desplazamiento y datos de competencia y uso de hablantes cuya socialización, adquisición y empleo del idioma en desplazamiento se hayan verificado con anterioridad a este, o bien cuando este era apenas incipiente).

A continuación, cotejamos los datos recogidos de los nueve hablantes en el contexto de desplazamiento de la lengua con la descripción profesional y con la histórica. Esta triangulación nos permite examinar tanto el cambio y la variación intergeneracionalmente como el posible cambio y la posible variación en dos contextos distintos: el previo y el posterior al desplazamiento. El recuento del análisis se sistematiza por las clases nominales descritas en las fuentes profesionales, a partir de las cuales se da cuenta de la convergencia o divergencia por grupos de hablantes (Grupo A: hablantes mayores de 50 años, identificados como A1, A2, A3 y A4; Grupo B: hablantes adultos de entre 30 y 40 años, identificados como B1 y B2; Grupo C: hablantes adolescentes, identificados como C1, C2 y C3).

Antes de entrar en detalle, conviene insistir en la necesidad de separar el sistema numeral del sistema de clasificación nominal. En general, se puede afirmar que los nueve hablantes manejan sin problema el sistema numeral (únicamente se registraron equivocaciones en dos hablantes), mientras que el sistema de clasificación nominal se encuentra claramente sujeto a variación y vacilación. Así, C2 se equivocó cuatro veces en la raíz numeral, pero se autocorrigió acertadamente de inmediato en tres de las ocasiones, por lo que solo se registró una 
divergencia (dijo 2-alargado para referirse a 1 wìm '1 mono congo'). Por su parte, B2 se equivocó en la raíz numeral dos veces (por ejemplo, dijo 1-alargado para aludir a 2 talók '2 lagartos').

\subsection{Clase humana}

Para la clase humana se presentaron tres tarjetas: 1 aláköl '1 mujer', 3 alà ' 3 niños' y 2 wëm '2 hombres'. En dos de las tarjetas (1 mujer y 3 niños), se aprecian sobre todo las cabezas de las personas, lo cual explica la variación en los datos. Así, en principio se esperaba elicitar formas con el clasificador humano en los tres casos, pero algunos hablantes emplearon el clasificador redondo, pues lo que contaron fue wökir 'cabeza', un sustantivo de la clase redonda.

Por este motivo, para 1 mujer, únicamente A1 empleó la forma 1-humano, mientras que A2, A3, A4, C1 y C2 dijeron 1-redondo. Por su parte, C3, B1 y B2 dijeron 1-plano, forma no explicable por sesgo del estímulo, debido a que, si bien podría pensarse que una representación plana elicitaría el uso del clasificador plano, ello habría ocurrido en todos los datos. En realidad, como se discutirá más adelante, estamos ante indicios de la extensión de la clase plana como resultado de la simplicación del sistema de clasificación nominal.

En el caso de 3 niños, todo el grupo A empleó la forma 3-humano, mientras que C3 usó 3-redondo, con un clasificador regularizado en - $k$ (mañák $k$ ). Difícilmente podría pensarse que se trate de la pervivencia de una forma antigua en este hablante, pues no se recogió de los hablantes mayores (algunos incluso de su propia familia). Se trata más bien de un rasgo idiolectal, una innovación por analogía, ya que esta misma persona emplea la forma mẫáa para 3-redondo en otros casos. Por su parte, B1, B2, C1 y C2 dijeron 3-plano.

Para la forma 2 hombres, imagen en la que sí se veían con más claridad los cuerpos, dos hablantes del grupo A emplearon 2-humano, mientras los otros dos usaron 2-redondo, al igual que B2, quizás porque nuevamente percibieron que las cabezas eran la parte más destacable. Todos los del grupo C dijeron 2-plano. De este modo, se aprecia también cómo impera la vacilación en algunos hablantes de los grupos B y C, quienes oscilan entre diferentes sufijos de clase, pero muestran ya una clara inclinación por emplear el sufijo de la clase plana.

\subsection{Clase redonda}

Se elicitaron quince formas de la clase redonda: 1 ajkố ' 1 canasta', 1 apì ' 1 ayote', 3 sabák '3 tambores', 2 ák '2 piedras', 3 ì '3 ollas', 3 sịal/sion' '3 huevos', 3 dikó/dakó ' 3 pejibayes (fruto)', 1 dìwö '1 sol', 1 tsiru'/tsuru' '1 cacao (fruto)', 1 síwö/si' '1 luna', 1 kuè '1 tortuga', 2 sawë '2 conejos', 2 pulè '2 caracoles', 1 dulú '1 arcoíris' y 3 dawás/duwás '3 años' (esta última mediante traducción). En cuanto a la morfología, en nuestros datos aparece la alomorfia $-k \sim-k a$ en los hablantes A1 y B2 en los numerales 1 y 2 (y -l para 3). Los demás emplearon los sufijos $-k$ o $-l$, según el numeral, en consonancia con las descripciones profesionales $(-k$ en 1 y $2,-l$ en 3), o bien una extensión del marcador - $k$ para el número 3, como se detallará más adelante.

De acuerdo con las descripciones, todos los frutos y verduras de forma esférica se adscriben a la clase redonda: ayotes, pejibayes, aguacates y cacaos. Hay que notar aquí que los ayotes considerados propios por los bribris son pequeños y muy esféricos, pero la ilustración que se empleó en la elicitación muestra un ayote bastante alargado. En principio, la adscripción a la clase sería automática en este caso: sea cual sea la forma, el ayote bribri prototípico es redondo y, por ende, se adscribe a la clase nominal redonda. Los cuatro hablantes del grupo A y el hablante B2 emplearon la forma 1-redondo, mientras que B1, C2 y C3 usaron 1-alargado, 
y C1 empleó 1-plano. Es decir, los hablantes más tradicionales automáticamente emplearon la forma de la clase redonda, independientemente de que se tratara de una imagen de un ayote alargado, mientras que dos de los hablantes más jóvenes y uno de los adultos privilegiaron la forma observable y se decantaron por el clasificador alargado.

En el caso de 3 pejibayes, la conformación de dos grupos es clara: todos los hablantes del grupo A emplearon la forma 3-redondo documentada desde finales de 1970: mẫáa (es decir, con el sufijo - $l$ idéntico al de la clase humana), B2 utilizó una forma de 3-redondo con el sufijo $-k$, mientras que todos los hablantes del grupo $\mathrm{C}$ y $\mathrm{B} 1$ usaron la forma de 3-plano. Para 3 frutos de cacao, todos emplearon 3-redondo, con excepción de B2 y C2, quienes usaron 3-alargado, nuevamente tal vez porque la ilustración mostraba un fruto un poco alargado, como es la mazorca de cacao en realidad. Es decir, de nuevo se muestran dos tendencias de cambio: la inclinación por la marcación morfológica de la clase plana, o bien la asignación a la clase alargada por fijarse en la forma exacta, en lugar de recurrir a la adscripción automática de los frutos a la clase redonda. En cualquier caso, nótese que los hablantes del grupo A son consistentes en los tres casos en cuanto a la asignación de los frutos a la clase redonda.

En lo concerniente a los objetos de forma redonda o esférica, las descripciones coinciden en adscribir explícitamente a la clase redonda las piedras, los tambores y las ollas. En el caso de 2 piedras, elicitado con una ilustración de dos piedras pequeñas relativamente esféricas, pero con cortes planos, todos los hablantes del grupo A, B2 y C3 usaron 2-redondo, mientras que B1 y C1 usaron la forma de 2-plano y C2 empleó 2-alargado. En lo que atañe a 3 ollas, A1, A2, A3 usaron 3-redondo con la forma mâñál; C3 empleó 3-redondo con la forma regularizada mânák . Por su parte, A4, B1, B2 y C1 utilizaron 3-plano, mientras C2 utilizó 3-alargado.

Para 3 tambores, A1, A2, C2 y C3 usaron 3-redondo, mientras que el resto de los hablantes empleó 3-plano. El tambor tradicional bribri es de forma cilíndrica, con un parche plano. Se podría esperar que, por lo tanto, si no se usa la asignación automática tradicional (clase redonda, por la redondez del corte del parche), se podría emplear la clase alargada, pero no ocurrió así. Por el contrario, apareció la forma de la clase plana incluso en hablantes del grupo A, lo cual hace pensar que o bien es posible que se imponga la percepción del volumen plano del parche, o bien se trata de extensión de la clase plana.

Finalmente, para 1-canasta, las descripciones profesionales coinciden en la asignación a la clase redonda, pero Lehmann (1920) explicítamente asigna este sustantivo a la clase marcada con el sufijo - $t$, junto con las camisas, los pantalones, los pájaros y los meses; esto es, la denominada contemporáneamente clase plana. Todos los hablantes del grupo A, B2 y C3 usaron la forma 1-redondo, mientras que el restó empleo 1-plano. Si bien lo más probable es que se trate de la extensión de la marcación de la clase plana por simplificación del sistema, la coincidencia con el dato de Lehmann no puede ignorarse.

En lo relativo a 3 huevos, estos, por su forma, se habrían de adscribir a la clase redonda. A1, A3, A4 y C3 usaron la forma 3-redondo (con sufijo - $l$ los tres primeros y con $-k$ el último). A2, B1, B2, C1 y C2 emplearon 3-plano. Por otra parte, el sustantivo dawás con el sentido de 'año' se ha documentado como perteneciente a la clase redonda en todos los autores, incluyendo Lehmann (1920). De nuevo, se hallan dos grupos en los datos: A2, B1 y todos los hablantes del grupo C usaron la forma de 3-plano, mientras los demás usaron 3-redondo. Con excepción de A2 (en cuyo caso no podemos explicar su producción), muy posiblemente estamos ante una extensión de la clase plana por simplificación del sistema; es decir, un cambio por obsolescencia. 
El sol y la luna, en tanto cuerpos celestes, suelen adscribirse a la clase redonda. Sin embargo, en Constenla et al. (1998) dìwö 'sol' se consigna como de la clase plana (al igual que cuando equivale a 'día' y 'hora'), mientras que Jara (2018) aclara que es de la clase redonda con el sentido de 'sol' y de la clase plana con el sentido de 'día, hora'. Del mismo modo, esta última autora asigna si' a la clase redonda con el significado de 'luna' y a la clase plana con el sentido de 'mes'.

Salvo C2 y C3, que utilizaron 1-redondo, los demás hablantes, incluyendo a todos los del grupo A, usaron la forma 1-plano para 1 sol, pese a que la ilustración no dejaba lugar a equívoco. Eso posiblemente signifique que la distinción semántica señalada o se ha perdido en gran medida, o bien está sujeta a oscilación dependiendo de factores no bien estudiados. Lo mismo sucede con 1 luna: únicamente A3 y C3 usaron la forma 3-redondo; los demás usaron 1-plano.

En un texto de tradición oral publicado en bribri en 1977 (Bozzoli, 1977, p. 103), aparece el sustantivo síwö 'luna' con el numeral böt '2-plano', mientras que dìwö 'sol' aparece con los numerales et '1-plano' y böt '2-plano', lo cual muestra que, en efecto, ambos sustantivos son susceptibles de adscribirse a la clase plana, puesto que muy probablemente se trate de un discurso conservador en lo relativo a la gramática y no de un indicio de obsolescencia. En este sentido, se requiere estudiar si se trata de una variación geolectal o si está sujeta al foco perceptivo y, por consiguiente, de opciones por las que el hablante puede optar "libremente".

En cuanto a los animales adscritos a la clase redonda, se incluyeron tres: kuè 'tortuga', sawé 'conejo' y pulè 'caracol'. En el caso de tortuga, si bien en Jara (2018) y en Jara y García (2013) este se consigna como de la clase redonda, en Margery (1982) y en Constenla et al. (1998) aparece como de la clase plana. Todos los hablantes usaron la forma 1-redondo, excepto A1, quien empleó 1-plano. Recuérdese que este hablante desempeña el cargo de awá y es quien posiblemente pueda catalogarse como el hablante más tradicional.

Por su parte, el conejo se consigna explícitamente como de la clase redonda en Constenla et al. (1998), Jara y García (2013) y Krohn (2014), mientras que en Margery (1982) aparece adscrito a la clase alargada. A1 empleó una forma que no pudimos reconocer con certeza; A2, A4, C1 y C2 usaron 2-alargado; B2 empleó la forma 2-redondo; y A3, B1 у C3 utilizaron la forma 2-plano. Como se puede apreciar, los datos muestran variación, con predominio de la clase alargada, si bien el uso de A3 de la forma 2-plano no resulta fácil de explicar, como sí en el caso de B1 y C3, si se considera que muy probablemente se trate de extensión de esta clase.

El sustantivo pulè 'caracol' aparece asignado explícitamente a la clase redonda en Margery (1982), Jara y García (2013) y Krohn (2014). Únicamente A1 y A4 emplearon la forma 2-redondo, frente a C2, que usó 2-alargado, y el resto de los hablantes, que se decantaron por 2-plano. De nuevo, podría tratarse o de una extensión de la marcación de la clase plana o de una posible variación por relevancia perceptiva no descrita.

El último caso es el de dulù 'arcoíris'. Este sustantivo solo aparece adscrito explícitamente a una clase en dos fuentes: a la clase redonda en Margery (1982) y a la alargada en Krohn (2014). Krohn (2014, p. 220) aduce, como explicación, que "Dulù es el nombre de una serpiente mítica que vive debajo de donde nace el sol y que se les revela a los humanos en forma de arcoíris". Margery (1982, p. 32) da cuenta de dos significados bajo la entrada de dulù: como 'arcoíris' (clase redonda) y como sustantivo mitológico (sin asignación de clase): "serpiente mítica que, según la creencia, vive debajo de donde nace el sol". 
Solamente A1 y C3 emplearon la forma 1-alargado. Recuérdese que el primero es el hablante más tradicional y gran conocedor de la historia sagrada de su pueblo, de modo que muy posiblemente se aplique la explicación de Krohn en este caso. Es probable que C3 se haya basado, para su selección de la categoría nominal, en la forma alargada del arcoíris, más que en la conceptualización mitológica. A2, A3 y C1 usaron la forma 1-redondo, en concordancia con lo anotado por Margery. Los demás hablantes utilizaron 1-plano, posiblemente por la extensión de la marcación de la clase plana.

\subsection{Clase alargada}

Se elicitaron doce sustantivos que, en principio, se adscribirían a la clase alargada: 3 nai ' 3 dantas', 2 sulì '2 venados', 1 wìm '1 mono congo', 3 skámoköl/skómoköllmóköl '3 cerbatanas', 1 tkabè/tchabè '1 culebra', 1 di' '1 río', 2 kö̀chi '2 chanchos', 1 buà '1 iguana', 2 kapö̀/kipò

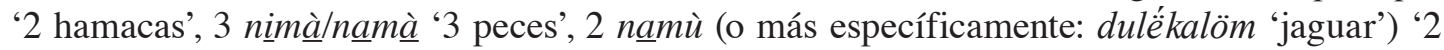
felinos, jaguares' y 2 talók '2 lagartos'. En cuanto a la morfología, la mayoría de los hablantes usó el sufijo -töm, pero A1 y A2 tendieron a simplificarlo en -tö.

En lo que atañe a los animales, todas las fuentes coinciden en que los mamíferos grandes, de cola larga o de cola con cierta longitud se categorizan en la clase alargada. También reptiles como los lagartos, las iguanas y las serpientes, así como los peces se incluyen en esta clase. Para 2 jaguares, emplearon la forma 2-alargado todos los hablantes, excepto A3, quien empleó 2-redondo, y C3, quien utilizó 2-plano. No es claro por qué A3 usó el sufijo de la clase redonda en este caso. Para 2 chanchos, de nuevo predomina la forma 2-alargado, excepto en el caso de A3 y C3, quienes utilizaron 2-plano, y B2, quien usó 2-redondo.

Para 2 lagartos se vuelve a encontrar más a menos la misma tendencia: empleo de 2-alargado por parte de todos los hablantes (o de 1-alargado en el caso de B2, quien se equivocó en la raíz numeral), excepto A3, C2 y C3, quienes usaron 2-plano. Son menos consistentes con esta tendencia los datos para 1 iguana: A1, A2 y C2 emplearon 1-alargado, mientras que A4, B2, C1 y C3 utilizaron 1-plano, y A3 y B1, 1-redondo. Tampoco son tan consistentes los datos para 1 culebra: A1, A2, C2 y C3 usaron 1-alargado, pero A3, A4 y B2 emplearon 1-plano, mientras que $\mathrm{C} 1$ usó 1-redondo y $\mathrm{B} 1$ declaró no saber.

En cuanto a 3 peces, A1, A2, A4 y C1 usaron 3-alargado, mientras que A3, B2, C2 y C3 utilizaron 3-plano, y B1, 3-redondo (con la forma regularizada mânáák). Recuérdese que, si bien en todas las fuentes profesionales y en Lehmann el sustantivo se adscribe a la clase alargada, en el Evangelio (1905) oscila entre esta y la clase plana, de modo que quizás pueda categorizarse en ambas clases dependiendo de a lo que se le dé mayor relevancia perceptiva (su longitud o su volumen).

En lo relativo a 3 dantas, 2 venados y 1 mono congo, surgió un dato que no había sido considerado inicialmente en el diseño del instrumento: A1, el hablante más tradicional, consideró que las tarjetas de la danta, el venado y el mono congo representaban animales muertos. Por este motivo, en los tres casos empleó la denominada clase "élka" por Constenla et al. (1998), la cual morfológicamente coincide con la clase de las plantas en pie y unidades de peso, y se emplea también para saínos, dantas y chanchos de monte muertos. Poco se sabe de esta clase, pues ningún trabajo a profundidad se ha realizado con respecto a cuándo se usa y si es de dominio general, además de que las fuentes que consignan la información son sumamente escuetas al respecto. 
Así, para 3 dantas, A1 empleó la forma mañáálka '3-animal muerto', para 2 venados usó bölka '2-animal muerto' y para 1 mono congo empleó élka '1-animal muerto'. En ninguno de los demás hablantes apareció el sufijo de esta clase. No puede saberse si se debe a que no realizaron la misma inferencia que A1 y simplemente consideraron que se trataba de animales vivos, o si esta clase no forma parte de su competencia lingüística (sea porque se perdió o porque no llegaron a adquirirla). Asimismo, debe notarse que la clase no parece estar restringida a las dantas, chanchos de monte y saínos muertos, sino que otros animales de más o menos su misma condición (tamaño, desplazamiento en cuatro patas), como los venados, podrían estar incluidos, ya sea porque así ha ocurrido desde el inicio de la gramaticalización de la clase o porque el alcance semántico se ha extendido.

Para 3 dantas, los demás hablantes se decantaron por las formas de la clase alargada (A2, B1 y C1), la clase redonda (B2, C2 y C3) y la clase plana (A3 y A4). Para 2 venados, la distribución fue entre la clase alargada (A2, A4, C1), la clase plana (A3, B1, C2 y C3), mientras que B2 usó böl, forma actual para 2-humano. Para 1 mono congo, predominó la forma 1-redondo (A2, B1, B2, C1 y C3), mientras que el sufijo de la clase alargada fue empleado por A3 y C2, y únicamente A4 usó 1-plano.

Debe notarse que las ilustraciones tanto de la danta como del mono congo destacan el cuerpo prominentemente redondo de estos animales, que la danta tiene la cola corta y que el mono congo aparece en posición erguida sobre una rama, mientras que del venado se aprecia su cuerpo alargado y relativamente delgado. Quizás estos detalles de forma expliquen, al menos parcialmente, la aparición del sufijo de la clase redonda para el conteo de la danta y el mono congo, pero no para el venado. Queda la duda, por tanto, de si el sistema es más flexible de lo que se ha descrito o de si toda esta oscilación e incluso vacilación en la asignación de las clases constituye un síntoma más del proceso de obsolescencia, como claramente parece inferirse para el caso de la aparición de formas de la clase plana.

Asimismo, se elicitaron datos para dos objetos (hamaca y cerbatana), así como para una entidad geográfica (di' 'río'). Para 3 cerbatanas, A1, A2, C2 y C3 usaron 3-alargado, mientras que A3, A4, B1 y C1 emplearon 3-plano, y B2 utilizó 3-redondo. Más o menos la misma tendencia se encuentra con respecto a hamaca: A1, A2 y C2 usaron 2-alargado, mientras que el resto empleó 2-plano. Si bien en dos de las fuentes se explicita que este sustantivo pertenece a la clase alargada (Margery, 1982 y Constenla et al., 1998), no puede descartarse que se pueda concebir también como una entidad plana, al igual que, por ejemplo, las prendas de vestir. En este caso en particular, por ende, no es posible determinar si la aparición del sufijo de la clase plana se debe a extensión por simplificación del sistema en obsolescencia o a una posibilidad de variación no descrita en el sistema tradicional o incluso a diferencias en el foco perceptivo.

Por último, para 1 río, se vuelve a hallar un comportamiento parecido: A1, A2 y C3 emplearon 1-alargado, mientras que A3, A4, B2 y C2 usaron 1-plano, y B1 y C1, 1-redondo. La forma sinuosa del río en la ilustración utilizada para la elicitación puede haber estimulado la aprición del sufijo de la clase redonda en este caso.

\subsection{Clase plana}

Se escogieron diecisiete sustantivos para elicitar formas de la clase plana: 2 tk $\underline{a}^{\prime} /$ tcho' '2 guacales', 3 sku' '3 bolsos', 1 ók '1 araña', 2 dakarò/krò '2 gallinas', 2 o' '2 hachas', 3 kabék '3 quetzales', 1 kula' '1 asiento', 2 bùlwak '2 abejas', 1 kulë' '1 batea', 1 aka $/ a k \underline{o}$ ' '1 
cama', 2 kua'kua '2 mariposas', 2 apàio '2 camisas', 3 kalöio ' 3 pantalones', 1 iñ $\underline{a}$ ' '1 tamal', 3 só '3 cucarachas', 3 kapalë/plë' '3 zompopas' y 3 si' '3 meses'. En cuanto a la morfología, predomina el alomorfo $-t$ por sobre $-t k$ en los datos elicitados.

Las fuentes coinciden en describir que insectos y arañas se adscriben a la clase plana. Según los datos recogidos de los nueve hablantes, es muy posible que así haya sido en el sistema más tradicional, como evidencia la sistematicidad con que al menos A1 y A2, los dos hablantes más tradicionales, optaron por formas de la clase plana en todos los casos. No obstante, se aprecia también que, posiblemente por el proceso del cambio lingüístico en marcha, algunos hablantes ya no se ciñen a esta categorización tradicional, sino que se fijan en la forma relativamente alargada o redonda del animal en cuestión.

Así se evidencia en 1 araña, pues el cuerpo del animal en la ilustración es claramente redondo. A1, A2, A4 y C1 emplearon 1-plano, pero A3, B1, B2 y C3 usaron 1-redondo, mientras que C2 utilizó 1-alargado. Para 2 abejas, todos los hablantes utilizaron 2-plano, con excepción de $\mathrm{C} 1$ y $\mathrm{C} 2$, quienes emplearon 2-alargado, sin duda porque el cuerpo se ve relativamente alargado en la ilustración. Lo mismo sucedió en el caso de 3 cucarachas: la mayoría usó 3-plano, pero A4, C1 y C2 utilizaron 3-alargado, y B2 empleó 2-redondo. Para 3 zompopas, solo dos hablantes usaron formas distintas a 3-plano: C1 empleó 3-alargado y B2 utilizó 3-redondo. En la ilustración, se muestran las zompopas vistas desde arriba, alargadas, con los extremos del cuerpo claramente esféricos. Para 2 mariposas, por el contrario, fue prácticamente absoluto el uso de 2-plano, salvo en el caso de C1, quien utilizó 2-alargado, y B2, que no supo responder. En este caso, la ilustración mostraba mariposas con las alas completamente extendidas y en perspectiva desde arriba, lo cual hacía resaltar el volumen plano.

En lo concerniente a las aves, para 2 gallinas predominó la forma 2-plano, excepto por C1 y C2, que usaron 2-alargado. La ilustración mostraba unas gallinas desde una perspectiva lateral y, por lo tanto, con una forma relativamente alargada. Con 3 quetzales, predominó también 3-plano, pero A4, C1 y C2 usaron 3-alargado. En este caso, la ilustración mostraba un quetzal en vuelo, con la cola muy larga y extendida.

En lo relativo a los objetos, parece imponerse el mismo principio. Así, en 2 guacales, si bien predominó la forma 2-plano, A2 usó 2-redondo y C2, 2-alargado. La ilustración mostraba un guacal desde una perspectiva desde arriba en plano picado, de modo que se nota la redondez de la base del guacal, así como su boquete redondo, pero el objeto tiene una prominencia bastante alargada en la sección que originalmente unía el fruto al árbol. Con el hacha ocurre lo mismo: el palo de esta es alargado. En este caso, C2 y C3 usaron 2-alargado, frente a los demás, que emplearon 2-plano, con excepción de B2, quien utilizó 2-redondo.

Por su parte, tanto el asiento como la batea también se ven desde arriba en plano picado, lo que resalta la redondez de estos objetos, además de sus bases planas. A1, A2, C2 y C3 usaron 1-plano para el asiento, mientras que A3, A4, B2 y C1 emplearon 1-redondo, y B1, 1-alargado. En el caso de la batea, todos los hablantes del grupo $\mathrm{C}$ utilizaron 1-redondo, frente al resto, que empleó 1-plano. La cama es plana, pero en la ilustración claramente se aprecia que es también alargada. Todo el grupo A más C1 usó en este caso 1-plano, mientras que C2 y C3 emplearon 1-alargado, y los dos del grupo B utilizaron 1-redondo, algo que resulta difícil de explicar a partir de la ilustración.

En principio, las prendas de vestir, así como los bolsos, se adscriben a la clase plana. La ilustración del bolso ( $s k u$ ') muestra que este es plano, pero con la cuerda para colgárselo estirada, de modo que se aprecia también como un objeto alargado; además, la parte del bolso 
en la que se guardan las cosas tiene una forma redondeada. Posiblemente por este motivo, si bien predominó la forma 3-plano, C3 y B2 usaron 3-redondo, mientras C2 empleó 3-alargado. Para 2 camisas también predominó la forma 2-plano, pero B1 y C3 usaron, inexplicablemente, 2-redondo. En 3 pantalones fue unánime el empleo de la forma 2-plano. Para 1 tamal también resultó absoluta la utilización de 1-plano.

Finalmente, la unidad de tiempo si' 'mes' es adscrita a la clase plana tanto en las descripciones profesionales como en Lehmann (1920) y en los datos del Evangelio (1905). Casi todos los hablantes emplearon la forma 3-plano en este caso, con excepción de A2 y B2, que usaron 3-redondo. En el caso de B2, el mismo hablante proporcionó una posible razón: afirmó emplear el sustantivo duás (forma reducida de dawás) tanto para el concepto de 'año' como para el de 'mes', lo que explicaría que use la clase redonda (dawás 'año' se adscribe a la clase redonda).

\subsection{Otras clases sortales: edificaciones y árboles en pie}

Para elicitar formas de la clase de edificaciones, se emplearon dos ilustraciones: una de la casa tradicional cónica (ù sulé) y otra de la casa tradicional rectangular (ölöwe). Las descripciones profesionales son muy escuetas al respecto. Margery (1982), en la entrada $\grave{u}$ 'casa', indica que pertenece a la clase plana; sin embargo, en el ejemplo de uso de esa palabra aparece la forma étkue, propia de la clase de edificaciones. Jara (2018) es más explícita y aclara que $\grave{u}$ es un sustantivo variable, que cuando se refiere a la casa cónica se adscribe a la clase redonda, pero cuando alude a la casa cuadrada actual se categoriza como de la clase plana. Constenla et al. (1998), por su parte, indican que ì pertenece a la clase de edificaciones.

En cuanto a 2 casas cónicas, resulta ininteligible en la grabación lo que dijo A1, pero el resto de los hablantes empleó la forma 2-redondo, con excepción de B2 y C2, quienes utilizaron 2-plano. Para 3 casas rectangulares o cuadradas, A1 es el único que aparentemente empleó la forma 3-edificación, aunque no con la forma documentada mañàttkue, sino con la forma mânáálwe; es decir, con un tema idéntico a 1-humano y no a 1-plano.

Para la clase de las plantas en pie, se incluyó la ilustración de 3 árboles. Solamente A1 empleó la forma 3-planta en pie (mañálka). Por el contrario, predominó la forma 3-plano, con excepción de C2, quien usó 3-alargado, y de A2, quien se decantó por 3-redondo, quizás porque en la ilustración sobresalen unas copas muy frondosas, frente a un tronco pequeño y delgado.

\section{Conclusiones}

Los indicios de variación y cambio lingüístico del sistema de clasificadores nominales del bribri tratados en este artículo deben examinarse de acuerdo con un factor primordial que posibilite sistematizarlos e intentar comprenderlos: el desplazamiento de la lengua. Así, en principio, no son atribuibles al proceso de obsolescencia la variación y el cambio que se puedan identificar en las descripciones y los corpus anteriores a la segunda mitad del siglo XX, así como en las descripciones llevadas a cabo por lingüistas profesionales y los corpus discursivos documentados desde la década de 1970, sobre todo cuando en estas tareas han estado involucrados hablantes tradicionales que adquirieron el idioma en un entorno sociocultural lingüísticamente rico y predominantemente monolingüe en bribri. 
Por su parte, es más posible que evidencien la variación y el cambio vinculados directamente con el desplazamiento los datos recabados ya avanzada la segunda mitad del siglo XX y durante el siglo XXI con hablantes relativamente jóvenes, presumiblemente más innovadores o con competencia lingüística más reducida en bribri (por ejemplo, semihablantes o hablantes parciales; ver Grinevald y Bert, 2011), o bilingües con el español como lengua cada vez más dominante, que adquirieron el bribri en un entorno sociocultural con creciente presencia cotidiana del español, en interacciones esporádicas y quizás no participativas en bribri (es decir, escuchando lo que otros hablaban, pero no produciendo); esto es, en un contexto de adquisición poco propicio y más incidental.

En este sentido, la acelerada y profunda transformación cultural de tinte hispanizante, así como el contacto prolongado y frecuente del bribri con el español y la acusada pérdida de dominios de uso del bribri en el contexto del desplazamiento han de mediar en la variación y en el cambio. Empleando la terminología habitual, podría pensarse en muy posibles cambios por obsolescencia. A continuación, esbozamos brevemente algunas conclusiones preliminares acerca de la variación y el cambio del sistema de clasificación nominal del bribri.

En términos de la teoría de la gramaticalización (Hopper y Traugott, 2003), se diría que el canal de gramaticalización en el caso del bribri habría sido: numeral + sustantivo clasificador de forma $>$ numeral + sufijo clasificador de forma. Según el principio identificado para el protochibcha (Constenla, 2008), los sufijos clasificadores resultantes más básicos deberían de ser los sortales de forma, y luego se habrían formado los demás paradigmas. No obstante, no está bien establecido cuál fue el desarrollo de la gramaticalización de cada uno de los paradigmas y, al no contar con la adecuada documentación de la lengua, es poco lo que se puede saber con certeza.

Con repecto a la incompletud de ciertos paradigmas, los datos históricos con que contamos hacen suponer que el sistema que se describió a partir de finales de 1970 no había sufrido reducción de formas por obsolescencia para ese entonces en lo que respecta a las clases redonda y plana. Los datos históricos corresponden a un momento cuando la lengua contaba con plena y absoluta vitalidad. Si se hipotetiza que quizás existieron formas regulares para 3-redondo y de ahí en adelante (es decir, con sufijo - $k$ ), o para 4-plano y de ahí en adelante (esto es, con sufijo - $t k \mathrm{o}-t)$, y que estas formas se sustituyeron por las de la clase humana, debemos suponer que se habría tratado de un cambio regular no mediado, incentivado o acelerado por el desplazamiento lingüístico, que en el caso del bribri no inició antes de mediados del siglo XX (Sánchez, 2009).

La documentación histórica nos sugiere que los paradigmas de las clases humana, redonda, plana y alargada ya habían adquirido su configuración actual desde finales del siglo XIX. Nuestra posición es, por consiguiente, que las formas de la denominada clase humana no "invadieron" los otros paradigmas. No se trata de que las formas con morfología propia para las clases redonda y plana (con $-k$ y $-t k \sim-t$, respectivamente) hayan desaparecido o hayan sido desplazadas por formas supletivas; es decir, tales paradigmas no se habrían reducido.

Tampoco es posible postular que, como resultado del desplazamiento del idioma, esa morfología propia (la que quedaría en los números de 1 a 2 en la clase redonda y de 1 a 3 en la clase plana) está "a punto de desaparecer" a favor de las formas de la clase humana, puesto que tales paradigmas han tenido su configuración actual al menos desde finales del siglo XIX, cuando la lengua contaba con plena vitalidad. La evidencia del cambio lingüístico 
por obsolescencia muestra, más bien, ya ahora sí en un contexto claro de desplazamiento, que se estaría produciendo una simplificación del sistema numeral + sistema de clasificación nominal, con el paradigma de la clase plana empleándose como el predominante para contar cualquier entidad.

Esta tendencia se explica al ser la clase plana la menos marcada de todas, puesto que se utiliza no solo para categorizar las entidades consideradas planas, sino también ciertos conceptos abstractos, y la serie de números con el sufijo de esta clase se usa asimismo para contar sin referencia particular a la naturaleza de la entidad (Jara, 2018). Por el contrario, postular que la clase humana ha "invadido" la clase redonda y la clase plana, que se ha "extendido" a estos paradigmas o que "suple" formas ante la desaparición de las propias de estas se topa con el inconveniente de que, semánticamente hablando, la clase humana es muy marcada: únicamente se adscriben a ella las personas y los seres míticos antropomórficos.

Los hablantes de menor competencia lingüística no suelen emplear la clase humana en lugar de las otras, sino que, además de la variación idiolectal y la posible asistematicidad y dubitación en el uso de las formas numeral + clasificador por obsolescencia, la tendencia más clara es la de emplear las formas de la clase plana por sobre las demás. De este modo, la clase plana, que es la menos marcada semánticamente, es la que se generaliza.

La otra tendencia que se aprecia en los datos de cambio por obsolescencia guarda relación con el foco perceptivo. Así, la forma tradicional de asignación de la clase en algunos casos (recuérdese como ejemplo paradigmático el caso de apì 'ayote', considerado tradicionalmente un sustantivo de la clase redonda) cede ante una percepción que asigna los sustantivos a una clase con un criterio más transparente: si algo se ve alargado (como el ayote de la ilustración usada como estímulo de elicitación), se cuenta entonces con la forma numeral + clase alargada. Así parece ocurrir con varios sustantivos: ayote, araña, gallina, hacha, arcoíris, quetzal, asiento, abeja, batea, cama, cacao y cucaracha.

El proceso de cambio lingüístico conlleva variación y coexistencia de soluciones diversas, hasta que alguna de ellas llega a consolidarse y las otras eventualmente desaparecen. Sin embargo, como hace notar Dorian (2010), en una lengua que ha estado poco sujeta a la presión normativa estandarizadora, como puede ocurrir en una sociedad demográficamente pequeña y no muy estratificada, cuyas interacciones cotidianas se realizan sobre todo de modo oral, es previsible que exista variación idiosincrática sin un valor sociosimbólico asociado.

La presunción de uniformidad en el sistema lingüístico en un estadio específico de este lleva a que las descripciones muchas veces se basen en uno o pocos hablantes y que se espere que sus usos representen el consenso. No es que no existan patrones y regularidades en la lengua de una sociedad pequeña, sino que se halla mayor variación sincrónica y los individuos se ven menos impulsados a ajustar sus usos a los de un grupo, a converger lingüísticamente. Ciertamente existen áreas de la gramática con formas cristalizadas y uniformes, mientras que otras están en proceso de consolidación y muestran una variación más o menos amplia, no solo determinada por factores intra y extralingüísticos, sino también relativamente libre e idiolectal. Es muy posible que así ocurra con el sistema de clasificación nominal en bribri, tanto en lo que concierne a su marcación morfológica como a su configuración semántica.

En este sentido, la forma mâñálwe '3-edificaciones' que recogimos de un hablante fluido tradicional, claramente formada usando como tema el numeral terminado en - $l$ (identificado como propio de la clase humana) más el sufijo we, muestra la pervivencia de una vía de gramaticalización distinta a la descrita en Constenla et al. (1998), en cuyo caso el 
tema es la forma numeral + clase plana marcada con el alomorfo -tk (por ejemplo, mânàt $\underline{a} w e$ '3-edificaciones'). Como ya se adelantó, existen claros indicios en la documentación histórica de que el paradigma de la clase de edificaciones para finales del siglo XIX e inicios del XX se formaba con -we sufijado a la base de plano hasta 3 (Pittier, 1898) o hasta 4 (Lehmann, 1920) y a partir de ahí sufijado a la base coincidente con la clase humana. La forma mânálwe muestra una posibilidad no documentada antes: que para 3 el tema sea también el terminado en $-l$ y no en $-t k$.

Es decir, es probable que la variación haya sido y sea mucho mayor de la descrita: habría hablantes con un paradigma de la clase de edificaciones completamente formado con el tema de plano y hablantes con un paradigma formado con el tema de plano hasta cierto numeral y con el actual tema de humano en los restantes; incluso podría ser que haya hablantes cuyo tema en todos los numerales sea el humano. Podría también ocurrir que las formas alternen de modo relativamente libre y que el hablante que dijo mañálwe en un momento diga también mâñàtkwe en otro.

Es evidente que, de acuerdo con la documentación profesional, algunos paradigmas difieren en el grado de completud en los distintos geolectos, ya sea porque existe el número, pero este no se marca con el sufijo de clase propio, o porque no existe el número tampoco. Así, para la clase alargada, Constenla et al. (1998) consignan la forma dabòptöm '10-alargado' (con el sufijo de alargado -töm), pero Jara (2018), para Coroma, consigna dabòm, coincidente con la forma de las clases humana, redonda y plana. Para la clase de plantas en pie, Constenla et al. (1998) consignan formas para todos los numerales, pero Jara (2018) solo para de 1 a 4 . Lo mismo ocurre para la clase de los racimos de pejibayes (Coroma) / racimos en general (Amubre y Salitre), la clase de los paquetes/bultos y la clase de las unidades de peso.

Se podrían aventurar dos interpretaciones: o en el geolecto de Coroma se han reducido ciertos paradigmas (posición sugerida por Krohn, 2014) o en esta variedad de la lengua no ha avanzado tanto la paradigmatización en tales casos, como sí ha sucedido en otros geolectos. De nuevo, no contamos con la información suficiente para decantarnos con completa certeza por una de estas posibilidades. En los datos de Pittier de finales del XIX, el paradigma de los "árboles y plantas" (el correspondiente al moderno "árboles/plantas en pie") aparece completo de 1 a 10. En Lehmann (1920), con la respectiva clase de "árboles de cacao y árboles frutales" parece ocurrir del mismo modo. El problema es que probablemente se trate de datos documentados con hablantes de regiones distintas a la de Coroma, así que no se puede saber si en esta variedad existió o no un paradigma completo de esta clase y se redujo, o si en realidad nunca llegó a completarse.

No resulta posible dilucidar esta cuestión, debido a que los paradigmas para los que aparentemente existe incompletud en Coroma no se recogen en la documentación histórica, a lo que se suma que la descripción profesional de la lengua durante las décadas de 1970 y 1980 se realizó principalmente con hablantes de otras regiones. No obstante, debe tenerse en cuenta siempre esta otra opción: esta variación puede estar ligada también al menor o mayor avance de la paradigmatización según el geolecto.

En lo relativo a la variación atinente a la adscripción de los sustantivos a una determinada clase, ya se anotó que un sustantivo como kuë 'tortuga' parece poder adscribirse a la clase redonda o la clase plana. Pese a que en Jara (2018) se tratan los sustantivos dìwö y si' con el sentido de 'sol' y de 'luna', respectivamente, como de la clase redonda, en nuestros datos de hablantes tradicionales parece que se pueden adscribir también a la plana con exactamente el 
mismo sentido. De hecho, en Constenla et al. (1998), dìwö se categoriza como de la clase plana, sea con el significado de 'sol' o con el de 'día, hora'. Ambos sustantivos aparecen también con formas numeral + clase plana en textos de tradición oral de finales de 1970 (Bozzoli, 1977), lo que hace pensar que difícilmente se trate de un cambio semántico vinculado a la obsolescencia. En el texto del Evangelio según san Juan de 1905, el sustantivo 'pez, pescado' aparece tanto con formas de la clase plana como de la clase alargada, pese a que en todas las descripciones aparece asignado a la clase alargada.

En algunos de los ejemplos aludidos, bien podría proponerse que estamos ante una variación determinada geolectalmente, pero ello debe estudiarse con detenimiento, sobre todo porque en el Evangelio se trata de datos de un mismo hablante. Por nuestra parte, hemos sugerido un factor que no parece haberse considerado explícitamente hasta el momento y que podría dar cuenta de la variación de al menos algunos sustantivos: quizás la adscripción (en los hablantes plenos y tradicionales) no siempre sea rígida, sino que, en lo que respecta al menos a las clases redonda, plana y alargada, dependa de un factor al que hemos denominado relevancia perceptiva o foco perceptivo.

De acuerdo con este factor, existirían sustantivos que pueden considerarse de dos clases distintas, pues dependería, en gran medida, del foco de percepción del hablante y este podría oscilar de un momento de habla a otro, según se priorice algún componente de la forma u otro. Así, un pez se puede ver tanto alargado (si la relevancia perceptiva está en la longitud) como relativamente plano (si el foco se pone en el volumen) y una tortuga se puede visualizar como de caparazón redondo o plano.

Puede ser que, incluso, en tales casos exista un espacio de elección según las preferencias de cada hablante. Que existe cierto margen determinado por detalles de observación de la forma de las entidades contabilizadas y que el foco perceptivo puede mediar en la opción seleccionada por el hablante queda patente en un dato como el que se encuentra en Constenla et al. (1998, p. 139): el sustantivo bö', referido a los leños, se categoriza en la clase plana si se trata de un leño corto, pero en la alargada si es largo. Así, la posibilidad de variación está presente en el sistema y ello puede incrementarse cuando el cambio se dispara por el proceso de obsolescencia.

La adscripción a las clases también puede haber variado diacrónicamente, sin que la obsolescencia sea un factor involucrado. La dificultad para esclarecer este asunto reside en que los datos tomados con anterioridad a la década de 1970 no solo son exiguos, sino que la mayor parte de las veces son omisos. Quienes tratan el tema con mayor detalle (Pittier, 1898; Lehmann, 1920) no consignan explícitamente la clase a la que pertenece cada sustantivo en sus listas léxicas ni tampoco ejemplifican exhaustivamente cada clase. Así las cosas, no todo se puede dilucidar, pero definitivamente se requiere más investigación.

\section{Bibliografía}

Bozzoli, M. E. (1977). Narraciones bribris. Vínculos, 3(1-2), 67-104.

Bozzoli, M. E. (1979). El nacimiento y la muerte entre los bribris. San José: Editorial de la Universidad de Costa Rica.

Constenla Umaña, A. (2004). El estudio de las lenguas de la Baja Centroamérica desde el siglo XVI hasta el presente. Estudios de Lingüística Chibcha, 23, 9-59. 
Constenla Umaña, A. (2008). Estado actual de la subclasificación de las lenguas chibchenses y de la reconstrucción fonológica y gramatical del protochibchense. Estudios de Lingüística Chibcha, 27, 117-135.

Constenla Umaña, A., Elizondo Figueroa, F. y Pereira Mora, F. (1998). Curso básico de bribri. San José: Editorial de la Universidad de Costa Rica.

Constenla Umaña, A., Margery Peña, E. Morales Stuart, R. y Pereira Mora, F. (1978). Bribri I. San José: Departamento de Publicaciones de la Universidad de Costa Rica.

Constenla Umaña, A., Margery Peña, E., Morales Stuart, R. y Torres Marín, A. (1979). Bribri II. San José: Departamento de Publicaciones de la Universidad de Costa Rica.

Dorian, N. (2010). Investigating Variation. The effects of social organization and social setting. Oxford: Oxford University Press.

Gabb, G. (1905). Evangelio según San Juan. Londres: British \& Foreign Bible Society.

Gabb, W. (1875). On the Indian Tribes and Languages of Costa Rica. Proceeding of the American Philosophical Society, 14, 483-602.

Gagini, C. (1917). Los aborígenes de Costa Rica. San José: Imprenta Trejos Hermanos.

Grinevald, C. (2007). The linguistic categorization of spatial entities: Classifiers and other nominal classification systems. En M. Aurnague, M. Hickmann y L. Vieu (Eds.), The categorization of spatial entities in language and cognition (pp. 93-121). Amsterdam: John Benjamins Publishing Company.

Grinevald, C. y Bert, M. (2011). Speakers and communities. En P. Austin y J. Sallabank (Eds.), The Cambridge Handbook of Endangered Languages (pp. 45-65). Cambridge: Cambridge University Press.

Hopper, P. y Traugott, E. (2003). Grammaticalization. Cambridge: Cambridge University Press.

Jara Murillo, C. (2018). Gramática de la lengua bribri. San José: E-Digital ED.

Jara Murillo, C. y García Segura, A. (2009). Se’ é’ yawö bribri wa. Aprendemos la lengua bribri. San José: Editorama S.A.

Jara Murillo, C. y García Segura, A. (2013). Se’ ttö bribri ie. Hablemos en bribri. San José: E-Digital ED.

Jones, M. y Singh, I. (2005). Exploring Language Change. Londres: Routledge.

Krohn, H. (2014). Semántica de los cuantificadores numerales en el bribri de Coroma. Estudios de Lingüística Chibcha, 33, 209-239.

Krohn, H. (2015). Los clasificadores numerales en el cabécar de Bajo Chirripó. Estudios de Lingüística Chibcha, 34, 9-31.

Künne, M. y Mackenbach, W. (Eds.). (2019). Las lenguas chibchas de Centroamérica en la obra de Walter Lehmann. San José: SIEDIN

Lehmann, W. (1920). Zentral-Amerika: Die Sprachen Zentral-Amerikas in ihren Beziehungen zueinander sowie zu Süd-Amerika und Mexico. (Vol. 2). Berlin: Verlag Dietrich Reimer. 
Margery Peña, E. (1982). Diccionario fraseológico bribri-español/español-bribri. San José: Editorial de la Universidad de Costa Rica.

Palosaari, N. y Campbell, L. (2011). Structural aspects of language endangerment. En P. Austin y J. Sallabank (Eds.), The Cambridge Handbook of Endangered Languages (pp. 100119). Cambridge: Cambridge University Press.

Pittier, H. (1898). Die Sprache der Bribri-Indianer in Costa Rica. Sitzungsberichte der Kaiserlichen Akademie der Wissenschaften, Philosophisch-Historische Classe, 138(6), 1-149.

Pittier, H. (1904). Numeral Systems of the Costa Rican Indians. American Anthropologists, 6(4), 447-458.

Sánchez Avendaño, C. (2009). Situación sociolingüística de las lenguas minoritarias de Costa Rica y Censos Nacionales de Población 1927-2000: Vitalidad, desplazamiento y autoafiliación etnolingüística. Filología y Lingüística, 35(2), 233-272.

Sánchez Avendaño, C. (2019). Obsolescencia estructural y revitalización lingüística: El sistema de clasificadores numerales del bribri y el juego de los números Tté shtáwok. En M. Haboud (Coord.), Lenguas en contacto: Desafios en la diversidad 1 (pp. 373-394). Quito: Centro de Publicaciones de la Pontificia Universidad Católica del Ecuador.

Stone, D. (1993). Las tribus talamanqueñas de Costa Rica. San José: Comisión Costarricense V Centenario del Descubrimiento de América.

Thiel, B. A. (1882). Apuntes lexicográficos de las lenguas y dialectos de los indios de Costa Rica. San José: Imprenta Nacional.

Tristán, J. (1913). Apuntes sobre la Lengua Bri-brí. (Texto manuscrito). 